\title{
Study of miR-10b regulatory mechanism for epithelial-mesenchymal transition, invasion and migration in nasopharyngeal carcinoma cells
}

\author{
WEIYI WANG \\ Department of Ear-Nose-Throat, Hunan Provincial People's Hospital, Changsha, Hunan 410005, P.R. China
}

Received June 12, 2017; Accepted September 27, 2017

DOI: $10.3892 / \mathrm{ol} .2017 .7172$

\begin{abstract}
The aim of the study was to investigate the miR-10b regulatory mechanism for epithelial-mesenchymal transition (EMT) and its effect on the proliferation and migration of nasopharyngeal carcinoma cells. RT-qPCR was used to detect the expression of miR-10b in CNE1 nasopharyngeal carcinoma cell line. The NP69 nasopharyngeal mucosal cell line was used to determine the expression of miR-10b after infection with lentivirus. The effect of miR-10b on the proliferation of NP69 was examined using cell counting kit-8. The effect of miR-10b on NP69 migration was examined using scratch assay. Western blot analysis was used to detect the effects of miR-10b on the expression of epithelial cell markers E-cadherin and $\beta$-catenin and mesenchymal cell markers fibronectin, N-cadherin, vimentin and matrix metalloproteinase-9 (MMP-9). The present study showed that miR-10b was highly expressed in CNE1 cells. The stable expression of miR-10b promoted the proliferation and migration of NP69 cells, downregulated the expression of epithelial cell markers E-cadherin and $\beta$-catenin, and upregulated the expression of mesenchymal cell markers fibronectin, N-cadherin, vimentin and MMP-9 resulting in cell EMT. In conclusion, miR-10b promotes the proliferation and migration of nasopharyngeal carcinoma cells, and induces EMT in nasopharyngeal carcinoma cells, thereby having the potential to become a new target for the treatment of nasopharyngeal carcinoma.
\end{abstract}

\section{Introduction}

Nasopharyngeal carcinoma is a malignant tumor of nasopharyngeal mucosa with high incidence in Guangdong, Guangxi and other regions in China (1). Epstein-Barr virus infection is closely associated with the carcinogenesis of nasopharyngeal

Correspondence to: Dr Weiyi Wang, Department of Ear-NoseThroat, Hunan Provincial People's Hospital, 61 Jiefang West Road, Changsha, Hunan 410005, P.R. China

E-mail: weiyi_wang03@163.com

Key words: nasopharyngeal carcinoma, epithelial-mesenchymal transition, invasion, migration, $\mathrm{miR}-10 \mathrm{~b}$ carcinoma. Nasopharyngeal cancer is highly malignant, has distant metastasis in the early stages, and is mainly located in cervical lymph nodes (2). Epithelial-mesenchymal transition (EMT) refers to the transformation of epithelial cells into motile mesenchymal cells, which is an important biological process for epithelial cell-derived malignant tumor cells to obtain migration and invasion capabilities. After EMT, cell morphology is altered, with increased and thickened cell surface fibers and increased pseudopodia. The expression of epithelial cell markers E-cadherin and $\beta$-catenin are decreased, whereas the expression of mesenchymal cell markers fibronectin, $\mathrm{N}$-cadherin and vimentin are increased, resulting in the increase of cell migration capacity and tumor metastasis (3-5). Following EMT, epithelial cells in a static state change into mesenchymal cells with a strong migration ability. Moreover, proteolytic enzymes, such as matrix metalloproteinase-9 (MMP-9), can degrade the basement membrane, thereby facilitating cells to invade the extracellular matrix (6). During the process of EMT in nasopharyngeal carcinoma cells, these markers have similar changes, but the mechanism leading to these changes remains unclear.

miRNAs affect the cell apoptosis, proliferation and differentiation processes by regulating the expression of target genes, and they are probably associated with tumor metastasis (7). Studies have reported that miRNAs are involved in the carcinogenesis and development of nasopharyngeal carcinoma (8-10). At present, changes of 35 kinds of miRNA expression levels have been found in nasopharyngeal carcinoma tissue (11). The mutual effect of miR141 and tumor-associated genes c-myc and PTEN promotes the carcinogenesis and development of tumors (12). MicroRNA microarray analysis has shownthereisasignificantdifference between miR-10bexpression in nasopharyngeal carcinoma cells and normal nasopharyngeal epithelial cells (13). To evaluate the role of miR-10b in the carcinogenesis and development of nasopharyngeal carcinoma, we used lentivirus to infect normal nasopharyngeal epithelial cells aiming to observe cell proliferation and migration changes, and to analyze the difference of expression levels in epithelial cell and stromal cell markers.

\section{Materials and methods}

Cells. The nasopharyngeal carcinoma cell line CNE1, was stored in our laboratory and cultured in RPMI-1640 medium 
containing $10 \%$ calf serum $(100 \mathrm{U} / \mathrm{ml}$ penicillin and $100 \mu \mathrm{g} / \mathrm{ml}$ streptomycin). The immortalized nasopharyngeal epithelial cell line NP69, was cultured with the same RPMI-1640 medium to which growth factors were added. The cells were cultured at $37^{\circ} \mathrm{C}$ in a $5 \% \mathrm{CO}_{2}$ incubator.

Quantitative PCR. Total RNA was extracted using the TRIzol kit (Invitrogen; Thermo Fisher Scientific, Inc., Waltham, MA, USA). RT-PCR was performed according to the manufacturer's instructions. The reverse transcription conditions were as follows: $25^{\circ} \mathrm{C}$ for $5 \mathrm{~min}, 42^{\circ} \mathrm{C}$ for $30 \mathrm{~min}, 85^{\circ} \mathrm{C}$ for $5 \mathrm{~min}$ to inactivate the RNA enzyme. qPCR was performed with U6 snRNA as the internal reference, and the reaction conditions were: Pre-denaturation at $95^{\circ} \mathrm{C}$ for $30 \mathrm{sec}$, denaturation at $95^{\circ} \mathrm{C}$ for $5 \mathrm{sec}$, followed by 40 cycles of annealing at $60^{\circ} \mathrm{C}$ for $30 \mathrm{sec}$ and extension at $72^{\circ} \mathrm{C}$ for $30 \mathrm{sec}$. The $\mathrm{Cq}$ values of miR-10b and U6 were calculated according to the amplification curves. Cq was calculated using the formula: $\mathrm{Cq}=\mathrm{Cq}_{\text {miR-10b- }} \mathrm{Cq}_{\mathrm{u} 6}$. The expression level of miR-10b in CNE1 and NP69 cells was compared using the $2^{-\mathrm{Cq}}$ method.

NP69 cells infected with lentivirus-miR-10b. The lentivirus system was constructed to express miR-10b. The sequence of miR-10b was inserted into the lentiviral plasmid pLP-VSVG. PLP-VSVG-miR-10b, pLP1 and pLP2 were co-transfected into $293 \mathrm{~T}$ cells, and after $48 \mathrm{~h}$, lentivirus-containing supernatant was collected. NP69 cells $\left(1 \times 10^{6}\right)$ were seeded in 6-well plates, cultured overnight into monolayer cells, and then incubated with lentivirus supernatant for $24 \mathrm{~h}$ to allow the lentivirus to infect cells. Lentivirus-infected cells were collected on the same day and days 2-6 after infection and the expression levels of miR-10b were detected by RT-qPCR. NP69 cells infected with blank PLP-VSVG served as the control.

CCK-8 assay. Lentivirus-infected NP69 cells were seeded in 96-well plates with $5 \times 10^{3}$ cells/well, and cultured overnight at $37^{\circ} \mathrm{C}$ in a $5 \% \mathrm{CO}_{2}$ incubator. Then, $10 \mu \mathrm{l}$ of the cell counting kit-8 (CCK-8) solution was added to each well, and incubated for $24 \mathrm{~h}$. The absorbance at a wavelength of $450 \mathrm{~nm}$ was measured. NP69 cells infected with the blank lentivirus served as the control. Cell viability was calculated using the formula: Cell viability $=($ the test well OD value - the blank well OD value)/(the control well OD value - the blank well OD value) $\mathrm{x} 100 \%$.

Cell scratch assay. Lentiviral-infected NP69 cells were cultured in 24-well plates with $5 \times 10^{4}$ cells/well, and incubated at $37^{\circ} \mathrm{C}$ in a $5 \% \mathrm{CO}_{2}$ incubator until the cell density reached $90 \%$. The cell monolayer was scraped in a straight line to create a scratch with a $10 \mu$ l pipette tip, and any debris was removed by washing the cells once with PBS and the cells were cultured continuously. Scratches were observed under a microscope (Olympus BX53; Olympus Corporation, Tokyo, Japan) at 24, 48 and $72 \mathrm{~h}$, the size of the scratches was measured, and the results represented the mean of the three experiments. CNE1 and NP69 cells without lentivirus infection served as controls.

Western blot analysis. NP69 cells were collected at $72 \mathrm{~h}$ after lentiviral infection and lysed with lysate. The lysate was separated by $10 \%$ sodium dodecyl sulphate-polyacrylamide gel electrophoresis and then transferred to a polyvinylidene

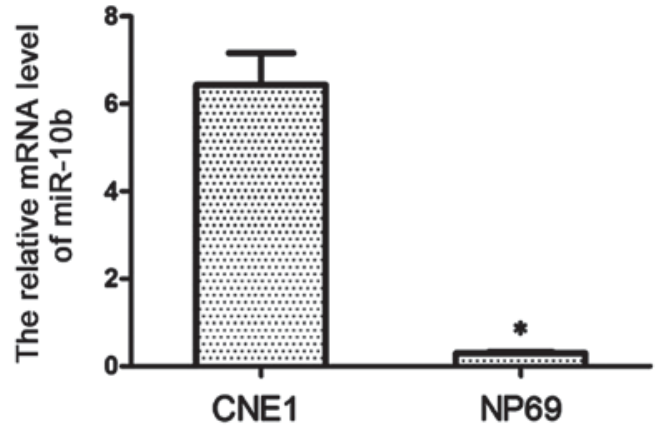

Figure 1. The expression levels of miR-10b in cells. The expression levels of miR-10b in CNE1 and NP69 cells determined by RT-qPCR. ${ }^{*} \mathrm{P}<0.01$.

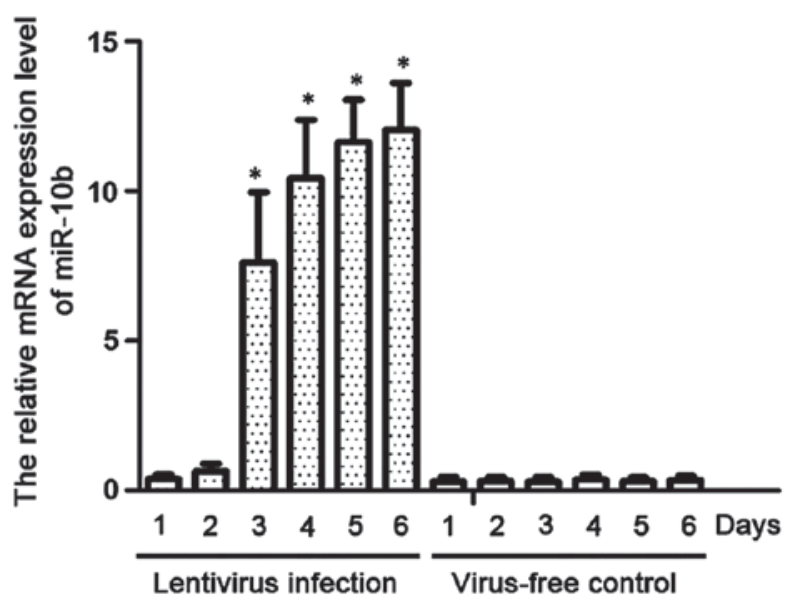

Figure 2. The expression levels of miR-10b after lentivirus infection in NP69 cells. The expression levels of miR-10b were detected by RT-qPCR at day $1,2,3,4,5$ and 6 after infecting NP69 cells with lentivirus. The blank pLP-VSVG was a virus-free control. " $\mathrm{P}<0.01$.

fluoride membrane and blocked with 5\% skim milk at room temperature for $2 \mathrm{~h}$. The membrane was incubated, using the following mouse anti human primary antibodies: Anti-E-cadherin, anti- $\beta$-catenin, anti-fibronectin, anti-vimentin and anti-MMP9 (dilution, 1:1,500; cat. nos. ab1416; ab22656; ab6328; ab8978; ab58803 respectively, purchased from Abcam plc., Burlingame, CA, USA) at room temperature for $1 \mathrm{~h}$. The membrane was then incubated with HRP-conjugated rabbit anti-mouse secondary polyclonal antibody (dilution, 1:2,500; cat. no. ab6728; Abcam plc.) for $1 \mathrm{~h}$. The HRP enzyme substrate was added and incubated for 5 min to develop color, and the immunoblotting result was recorded using a fully automated western blot WEs analysis system (ProteinSimple, San Jose, CA, USA). The density of each band was determined by ImageJ software, and $\beta$-actin was used as the internal reference. CNE1 and NP69 cells infected with blank lentivirus were used as controls. The relative expression level was calculated as the ratio of the assessed protein and $\beta$-actin and expressed as the mean \pm standard deviation $(n=3)$.

Statistical analysis. Data were expressed as mean \pm standard deviation, the difference between two groups was compared with the Student's t-test, and multiple group comparison was performed using Fisher's LSD test. $\mathrm{P}<0.05$ was considered to indicate a statistically significant difference. 


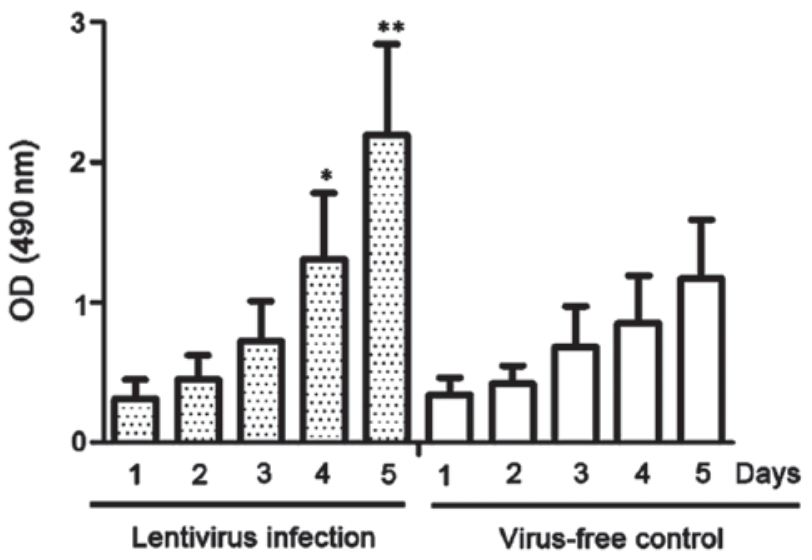

Figure 3. The proliferation of NP69 cells after infection with lentivirus. The proliferation of NP69 cells was detected by CCK-8 assay at day 1, 2, 3, 4 and 5 after infection with lentivirus. NP69 cells infected with miR-10b lentivirus, and the blank pLP-VSVG was a virus-free control. ${ }^{*} \mathrm{P}<0.05$; ${ }^{* * *} \mathrm{P}<0.01$; CCK- 8 , cell counting kit-8.

\section{Results}

miR-10b expression in cells. The expression of miR-10b in CNE1 cells was detected by RT-qPCR. As shown in Fig. 1, the expression level of miR-10b in CNE1 cells was significantly higher than that in NP69 cells $(\mathrm{P}<0.01)$, and miR-10b was almost absent in NP69 cells.
miR-10b expression in lentivirus-infected NP69 cells. We established a cell line stably expressing miR-10b by infecting NP69 cells with lentivirus. RT-qPCR was used to detect the expression levels of miR-10b. As shown in Fig. 2, miR-10b was highly expressed on day 3 after lentiviral infection, and its level on day 5 was significantly higher than that of NP69 cells with blank lentiviral infection $(\mathrm{P}<0.01)$.

miR-10b promotes NP69 cell proliferation. A CCK-8 assay was used to detect the proliferative ability of lentivirus-infected NP69 cells. As shown in Fig. 3, the proliferation of NP69 cells stably expressing miR-10b was significantly more rapid than that of NP69 cells with no lentivirus infection at day 4 after infection $(\mathrm{P}<0.05)$.

miR-10b promotes the migration of NP69 cells. The effect of miR-10b on the migration of NP69 cells was examined using a cell scratch assay. As shown in Fig. 4 and Table I, following cell scratching, CNE1 and NP69 cells expressing miR-10b grew and covered half of the scratches at $48 \mathrm{~h}$, and almost all the scratches after $72 \mathrm{~h}$. By contrast, NP69 cells in the control group did not cover half of the scratches after $72 \mathrm{~h}$. miR-10b promoted the migration of NP69 cells in a time-dependent manner. The difference in expression levels of miR-10b between CNE1 and NP69 cells led to a difference in the cell migration capacity, thereby further resulting in cancer cell metastases.
A

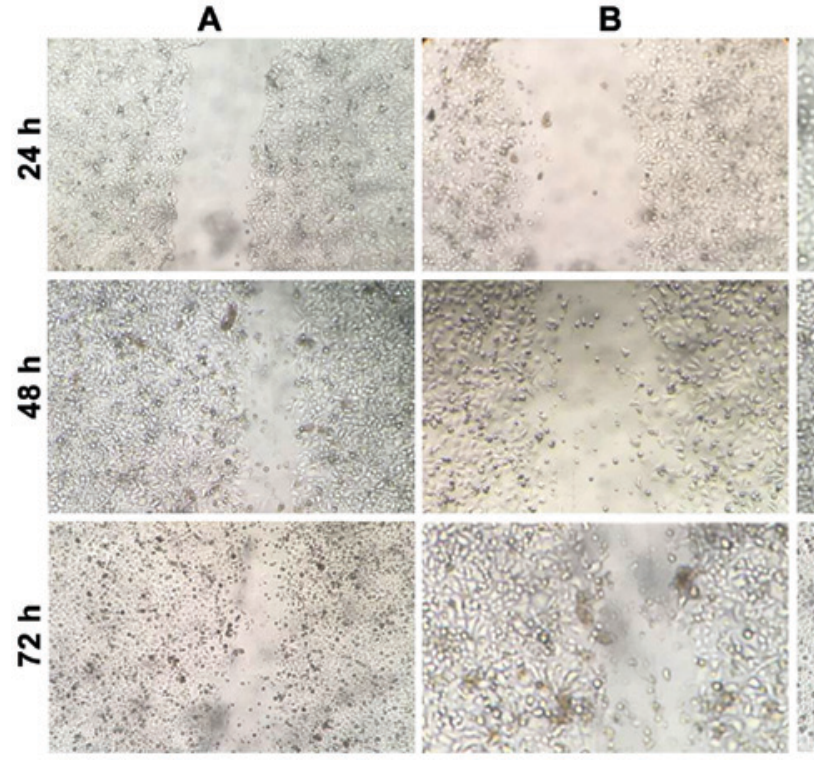

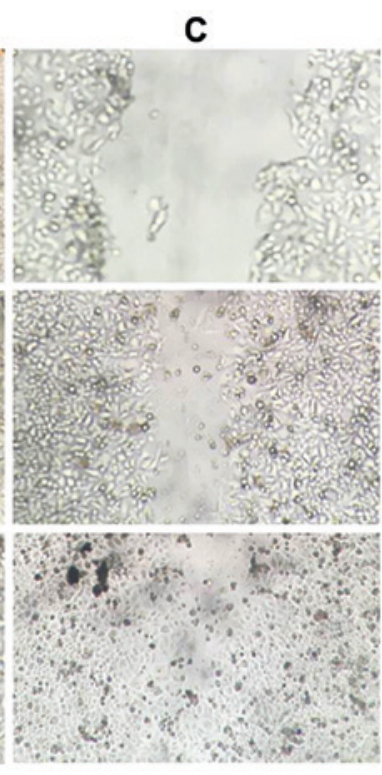

Figure 4. Scratch testing of NP69 cells infected with miR-10b lentivirus. The effect of miR-10b on cell migration ability detected by cell scratch assay at day 1, 2 and 3 after NP69 cells were infected with lentivirus. (A) NP69 cells infected with lentivirus-miR-10b, (B) NP69 cells infected with blank lentivirus, and (C) nonlentivirus-infected CNE1 cells.

Table I. Cell scratch size (mean \pm standard deviation, $n=3$ ).

\begin{tabular}{lccrr}
\hline Scratch size $(\mu \mathrm{m})$ & $24 \mathrm{~h}$ & $48 \mathrm{~h}$ & $72 \mathrm{~h}$ & P-value \\
\hline NP69 cells stably expressin miR-10b & $21.7 \pm 1.4$ & $10.7 \pm 2.3$ & $4.2 \pm 1.9$ & $<0.01$ \\
NP69 cells infected with blank lentivirus & $25.5 \pm 3.2$ & $19.7 \pm 4.3$ & $15.1 \pm 3.7$ & $<0.05$ \\
CNE1 cells & $32.6 \pm 2.5$ & $11.8 \pm 3.1$ & $1.3 \pm 0.4$ & $<0.01$ \\
\hline
\end{tabular}




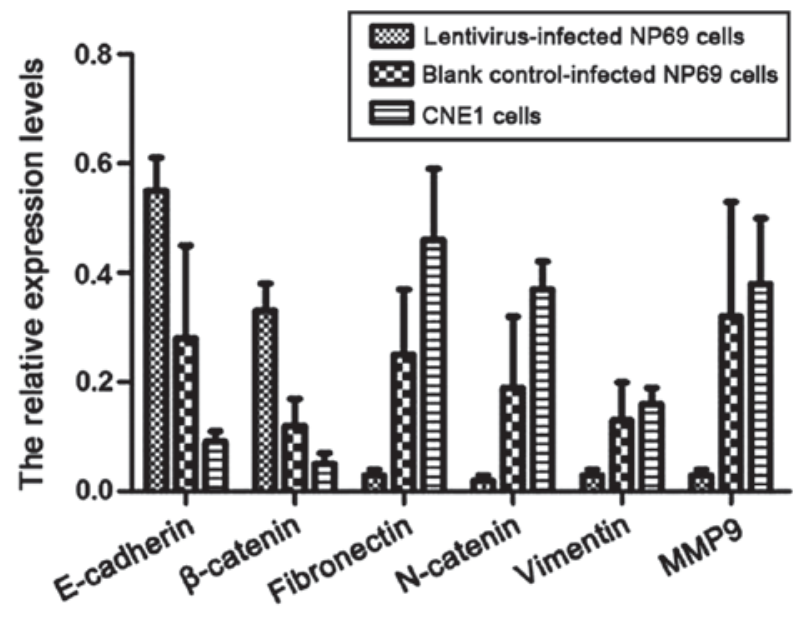

Figure 5. The expression levels of epithelial cell and stromal cell markers. The expression levels of epithelial cell and stromal cell markers were detected by western blot analysis, and CNE1 cells served as a control.

The expression levels of epithelial cells and stromal cell markers. Western blot analysis was used to detect the expression levels of epithelial cells and interstitial cell markers in CNE1 cells and lentivirus-infected NP69 cells expressing miR-10b. As shown in Fig. 5, the expression levels of E-cadherin and $\beta$-catenin in CNE1 and NP69 cells stably expressing miR-10b were significantly decreased compared to NP69 cells with no miR-10b expression $(\mathrm{P}<0.05)$. By contrast, the expression levels of stromal cell markers, fibronectin, $\mathrm{N}$-catenin, vimentin and MMP-9 were significantly increased $(\mathrm{P}<0.05)$.

\section{Discussion}

MicroRNAs regulate gene expression at transcriptional levels, and increasing research has focused on the role of microRNAs in the carcinogenesis and development of tumors. Previous findings have shown there is a difference in terms of the expression of miR-10b between nasopharyngeal carcinoma and normal nasopharyngeal mucosa tissue (12). The present findings showed that miR-10b expression in the CNE1 nasopharyngeal carcinoma cell line was higher than that in normal nasopharyngeal mucosa. The expression of epithelial cell markers E-cadherin and $\beta$-catenin, decreased after NP69 cells were infected with lentivirus and expressed miR-10b. E-cadherin enhances cell-cell adhesion, and its downregulation can decrease cell adhesion and increase cell motility through the basement membrane $(14,15)$. The expression of stromal cell markers fibronectin, N-cadherin, vimentin and MMP-9, was increased and the cell migration ability was enhanced, indicating that miR-10b promoted the EMT of nasopharyngeal carcinoma cells. miR-10b promoted tumor cell invasion and migration by downregulating the expression of KLF4 (16) and as a direct target of miR-10b, KLF4 was capable of inhibiting tumor cell invasion and migration (17), which could be used for target for further study.

In summary, the present findings show that miR-10b is involved in the EMT of nasopharyngeal carcinoma cells, promotes cell proliferation and migration and is closely associated with the metastasis of nasopharyngeal carcinoma. Further research is needed to elucidate the molecular mechanism of miR-10b regulating the EMT of nasopharyngeal carcinoma cells. miR-10b is expected to be a key target in the treatment of nasopharyngeal carcinoma, providing new opportunities for the development of new targeted therapies.

\section{References}

1. Spano JP, Busson P, Atlan D, Bourhis J, Pignon JP, Esteban C and Armand JP: Nasopharyngeal carcinomas: An update. Eur J Cancer 39: 2121-2135, 2003.

2. Lee AW, Poon YF, Foo W, Law SC, Cheung FK, Chan DK, Tung SY, Thaw M and Ho JH: Retrospective analysis of 5037 patients with nasopharyngeal carcinoma treated during 1976-1985: Overall survival and patterns of failure. Int J Radiat Oncol Biol Phys 23: 261-270, 1992.

3. He YX, Song XH, Zhao ZY and Zhao H: HOXA13 upregulation in gastric cancer is associated with enhanced cancer cell invasion and epithelial-to-mesenchymal transition. Eur Rev Med Pharmacol Sci 21: 258-265, 2017.

4. Bu JQ and Chen F: TGF- $\beta 1$ promotes cells invasion and migration by inducing epithelial mesenchymal transformation in oral squamous cell carcinoma. Eur Rev Med Pharmacol Sci 21: 2137-2144, 2017.

5. Thiery JP and Sleeman JP: Complex networks orchestrate epithelial-mesenchymal transitions. Nat Rev Mol Cell Biol 7: 131-142, 2006.

6. Chang JY, Wright JM and Svoboda KK: Signal transduction pathways involved in epithelial-mesenchymal transition in oral cancer compared with other cancers. Cells Tissues Organs 185: 40-47, 2007.

7. Sarkar FH, Li Y, Wang Z, Kong D and Ali S: Implication of microRNAs in drug resistance for designing novel cancer therapy. Drug Resist Updat 13: 57-66, 2010.

8. Wang LJ, Chou YF, Chen PR, Su B, Hsu YC, Chang CH and Lee JW: Differential miRNA expression in repeated recurrence of nasopharyngeal carcinoma. Cancer Lett 344: 188-194, 2014.

9. Plieskatt JL, Rinaldi G, Feng Y, Levine PH, Easley S, Martinez E, Hashmi S, Sadeghi N, Brindley PJ, Bethony JM, et al: Methods and matrices: Approaches to identifying miRNAs for nasopharyngeal carcinoma. J Transl Med 12: 3, 2014.

10. Liu N, Cui RX, Sun Y, Guo R, Mao YP, Tang LL, Jiang W, Liu X, Cheng YK, He QM, et al: A four-miRNA signature identified from genome-wide serum miRNA profiling predicts survival in patients with nasopharyngeal carcinoma. Int J Cancer 134: 1359-1368, 2014.

11. Chen SJ, Chen GH, Chen YH, Liu CY, Chang KP, Chang YS and Chen HC: Characterization of Epstein-Barr virus miRNAome in nasopharyngeal carcinoma by deep sequencing. PLoS One 5: e12745, 2010

12. Zhang L, Deng T, Li X, Liu H, Zhou H, Ma J, Wu M, Zhou M, Shen S, Li X, et al: microRNA-141 is involved in a nasopharyngeal carcinoma-related genes network. Carcinogenesis 31: 559-566, 2010.

13. Chen HC, Chen GH, Chen YH, Liao WL, Liu CY, Chang KP, Chang YS and Chen SJ: MicroRNA deregulation and pathway alterations in nasopharyngeal carcinoma. Br J Cancer 100: 1002-1011, 2009

14. Sánchez-Tilló E, Lázaro A, Torrent R, Cuatrecasas M, Vaquero EC, Castells A, Engel $\mathrm{P}$ and Postigo A: ZEB1 represses E-cadherin and induces an EMT by recruiting the SWI/SNF chromatin-remodeling protein BRG1. Oncogene 29: 3490-3500, 2010.

15. Huber GF, Züllig L, Soltermann A, Roessle M, Graf N, Haerle SK, Studer G, Jochum W, Moch H and Stoeckli SJ: Downregulation of E-Cadherin (ECAD) - a predictor for occult metastatic disease in sentinel node biopsy of early squamous cell carcinomas of the oral cavity and oropharynx. BMC Cancer 11: 217, 1-8, 2011.

16. Xiao H, Li H, Yu G, Xiao W, Hu J, Tang K, Zeng J, He W, Zeng G, Ye Z, et al: MicroRNA-10b promotes migration and invasion through KLF4 and HOXD10 in human bladder cancer. Oncol Rep 31: 1832-1838, 2014.

17. Tian Y, Luo A, Cai Y, Su Q, Ding F, Chen H and Liu Z: MicroRNA-10b promotes migration and invasion through KLF4 in human esophageal cancer cell lines. J Biol Chem 285: 7986-7994, 2010. 